\title{
Dermatoglyphs in duplication of the thumb
}

\section{HIROSHI SHIONO AND TOSHIHIKO OGINO}

From the Department of Legal Medicine, Sapporo Medical College, S-1 W-17 Chuo-ku; and the Department of Orthopaedic Surgery, School of Medicine, Hokkaido University, N-14 W-5 Kita-ku, Sapporo 060, Japan

SUMMARY The dermatoglyphs of 13 Japanese (eight males and five females) with duplication of the thumb were studied. The dermal patterns on the thumb were compared with those on the extra digit.

A whorl on the thumb was associated with a whorl on the extra digit in two cases, a radial loop in four cases, and an arch in two cases. Where the thumb pattern was a loop the pattern on the extra digit was a loop in all three cases.

Where the thumb and extra digit are both well developed the pattern tends to be the same on both digits. When the extra digit is poorly developed it tends to have a different pattern from the thumb.

With the rapid development of human cytogenetics and the discovery of new chromosomal aberrations in man, the value of dermatoglyphs in clinical medicine has been proved.

Cummins ${ }^{12}$ used dermatoglyphs of patients with polydactyly and other malformations of the hands and feet to study factors affecting ridge growth and differentiation. Since then, no reports on dermatoglyphs in polydactyly have been published.

Received for publication 10 August 1979
The purpose of this study is to compare the dermal patterns of the thumb with those of the extra digit.

\section{Subjects and methods}

Thirteen Japanese patients (eight males and five females) with duplication of the thumb were studied. Their ages ranged from 1 month to 4 years. They were apparently healthy apart from having the
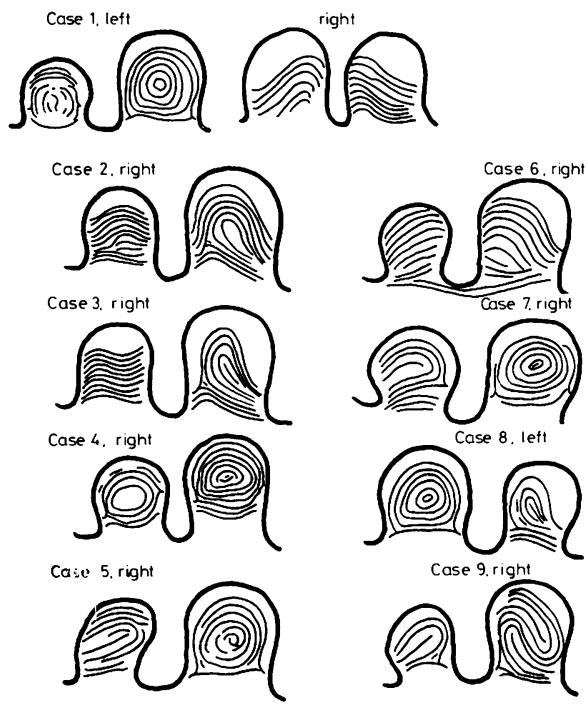

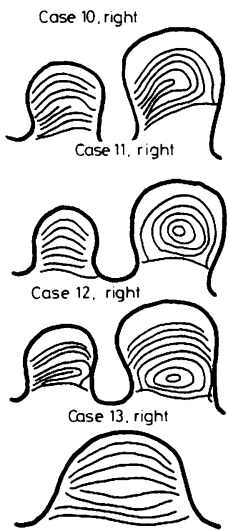

FIGURE Diagram of the relationship between the thumb and the extra digit. 
extra digit, and patients with the Rubinstein-Taybi syndrome are not included. One patient had duplication of both thumbs, one the left thumb, and ten the right thumb. The thumbs of the remaining patient were broad and did not seem to be duplicated, but polydactyly was shown on $x$-rays (case 13, figure).

Fingerprints were recorded using the Hollister Finger Print method, and palm prints were recorded with an ink pad.

\section{Results}

The dermatoglyphs of 13 patients were analysed, and the relationship between dermal patterns of the thumb and the extra digit was investigated.

The results obtained are shown in the figure and in tables 1 and 2. There was no pattern on the digits of cases 1 and 6 (figure). When the thumb and the extra digit are both well developed, they have the same pattern which tends to be a whorl. When the thumb and the extra digit are both poorly developed, they have an arch pattern or no pattern at all.

A true hypothenar pattern $\left(\mathrm{L}^{\mathrm{r}}\right)$ was observed on both palms of only one patient. The thenar, second, third, and fourth interdigital loops of patients with duplication of thumb are shown in table 2 . No thenar pattern was observed in any of the patients.

TABLE 1 The relationship between dermal pattern of thumb and extra digit

\begin{tabular}{lll}
\hline $\begin{array}{l}\text { Dermal pattern of } \\
\text { thumb }\end{array}$ & $\begin{array}{l}\text { Dermal pattern of } \\
\text { extra digit }\end{array}$ & No \\
\hline Whorl & Whorl & 2 \\
Whorl & Radial loop & 4 \\
Whorl & Arch & 2 \\
Ulnar loop & Arch & 2 \\
Radial loop & Arch & 1 \\
Large arch* & No pattern & 1 \\
No pattern & & 2 \\
Total & & 14 \\
\hline
\end{tabular}

*The thumbs were broad and apparently not duplicated, but duplication was demonstrated by $x$-rays.

TABLE 2 Percentage frequencies of thenar, second, third, and fourth interdigital loop patterns

\begin{tabular}{|c|c|c|c|c|c|c|c|c|}
\hline & \multicolumn{4}{|c|}{ Left hand } & \multicolumn{4}{|c|}{ Right hand } \\
\hline & $T$ & 2 & 3 & 4 & $T$ & 2 & 3 & 4 \\
\hline $\begin{array}{l}\text { Patients } \\
544 \text { male }\end{array}$ & 0.0 & $7 \cdot 1$ & $14 \cdot 3$ & $57 \cdot 1$ & 0.0 & $7 \cdot 1$ & $35 \cdot 7$ & $21 \cdot 4$ \\
\hline $\begin{array}{l}\text { controls } \\
129 \text { female }\end{array}$ & $1 \cdot 9$ & 0.9 & $6 \cdot 7$ & $56 \cdot 7$ & 0.0 & 0.4 & $16 \cdot 8$ & $50 \cdot 6$ \\
\hline controls & $5 \cdot 4$ & $3 \cdot 2$ & $12 \cdot 1$ & $78 \cdot 2$ & $3 \cdot 1$ & $5 \cdot 3$ & $32 \cdot 2$ & $67 \cdot 2$ \\
\hline
\end{tabular}

A simian crease was observed in $14.3 \%$ of the patients' left hands and in $7 \cdot 1 \%$ of their right hands. In the male and female controls, the frequencies were $9.8 \%$ in each hand.

\section{Discussion}

Cummins $^{12}$ found a relationship between development of the duplicated digits and the types of associated fingerprint pattern. He found that an imperfectly developed extra digit or a digit joined to its neighbour has a different pattern from the adjacent digit, and that a completely duplicated and separated extra digit tends to have the same type of pattern as the digit it duplicates. However, the relationship between duplication of the thumb and dermal pattern has not been investigated in detail.

Recently, in orthopaedic surgery, especially hand surgery, dermatoglyphs have started to be used for clinical purposes. Some abnormal dermal patterns in congenital malformations of the hands and feet suggest that aetiological factors operate in the early stages of the embryo. These patterns are completed by the 20th week and remain unchanged apart from increase in size and possible distortion by injury. Thalidomide is known to interfere with the normal development of ridge patterns.

According to the hypothesis of Mulvihill and Smith, ${ }^{3}$ just as the site of the volar pad indicates the location of patterns, certain mathematical concepts permit a geometric explanation for the genesis of particular types of patterns, such as arches, radial and ulnar loops, and whorls. The final pattern may be interpreted as the consequence of the height and contour of the volar pad at the critical time when ridges are developing: a low pad with little disruption of the parallel lines results in an arch, a high pad producing a whorl, and a pad of intermediate height producing a loop. Furthermore, a pad with a steeper side on the radial aspect of the fingertip would lead to an ulnar loop. This hypothesis is consistent with the dermal patterns in duplication of the thumb.

In our cases, a whorl on the thumb was associated with a whorl on the extra digit in two cases, a radial loop in four cases, and an arch in two cases. Where the thumb pattern was a loop the pattern on the extra digit was a loop in all three cases.

Where the thumb and extra digit are both well developed the pattern tends to be the same on both digits. When the extra digit is poorly developed it tends to have a different pattern from the thumb. In the combination of ulnar loop and arch pattern, the extra digit had an arch pattern. 
Dermal patterns might therefore be quite helpful in investigating the aetiology of duplication of the thumb.

\section{References}

1 Cummins H. Epidermal ridge configurations in developmental defects with particular reference to ontogenetic factors which condition ridge direction. Am $J$ Anat $1926 ; 38: 89-151$.
2 Cummins H. Spontaneous amputation of human supernumerary digits pedunculated postminimi. Am $J$ Anat $1932 ; 51: 381-416$.

3 Mulvihill JJ, Smith DW. The genetics of dermatoglyphics. J Pediatr 1969;75:579-89.

Requests for reprints to Dr Hiroshi Shiono, Department of Legal Medicine, Sapporo Medical College, S-1 W-17 Chuo-ku, Sapporo 060, Japan. 